\title{
An appraisal of ketamine in the dressing of burns
}

\author{
C. M. WARD* \\ F.R.C.S. \\ A. W. Diamond \\ F.F.A.R.C.S. \\ * Department of Plastic Surgery, and Department of Anaesthesia, Frenchay Hospital, Bristol
}

\begin{abstract}
Summary
The use of ketamine to provide anaesthesia for the dressing and application of graft to burned patients has been assessed. In a small number of severely burned patients, it was found to be most satisfactory provided that the circumstances in which it was used were carefully controlled.
\end{abstract}

\section{Introduction}

ChangING the dressings of patients with burns can be a distressing and painful experience which may, nevertheless, need to be frequently repeated. Relief of the pain and distress may be provided by the judicious use of conventional analgesics. The recent development of new potent analgesics has stimulated interest in their application to this problem. To be suitable for use in this field, an agent should satisfy certain conditions:

(1) There should be easy access to the whole burned area, and it should be possible to move the patient freely, without jeopardizing his airway or cardiovascular state; (2) it is important that an area to which split skin is to be applied should remain dry so that the graft can adhere; (3) the patient should not move excessively during the dressing; (4) induction and recovery should be pleasant; (5) minimal nursing care should be required in the recovery period; (6) there should be minimum interference with the patient's nutrition; (7) the agent used should be so acceptable to the patient as to be useful on many occasions, if necessary. Acquired tolerance should not be a characteristic.

A technique had been developed in the Burns Unit at Frenchay Hospital which combined a low dose of neuroleptanalgesia with premixed nitrous oxide and oxygen (Baskett, 1972). The technique was successful in a substantial number of patients; however, in a few, its effect was clearly inadequate. For this reason, it was decided to assess the value of ketamine and methoxyflurane in the provision of analgesia for burns dressings. It became clear in the early stages of the comparison that methoxyflurane was less effective than the neuroleptanalgesia technique that it was

\footnotetext{
* Present address: Department of Plastic Surgery, Odstock Hospital, Salisbury.
}

to replace. The assessment of ketamine was therefore $\stackrel{\vec{\circ}}{\rightarrow}$ continued at the Burns Unit to determine its suit- $\vec{\omega}$ ability as a burns dressing analgesic.

\section{Material}

Ketamine anaesthesia was provided for patients $\mathrm{N}$ following a request from the surgical staff. It was: most frequently requested for patients with a burn of substantial proportions, that is $25 \%$ or more in $N$ adults and $15 \%$ or more in children. It was occa-o sionally also given to patients who were extremely nervous, although not severely burned. This group $\vec{\nabla}$ represented only about $12 \%$ of the patients admitted을. to the unit and a number so small as to limit the extent of this paper to an initial report.

\section{Method}

Patients with burns at Frenchay Hospital afe submitted to the primary management of their burns, that is the removal of slough and adherent eschar, and the taking of split skin for grafting, in the operating theatre. An appropriate, conventional, $\overrightarrow{\vec{O}}$ anaesthetic technique, which may or may not involve 3 ketamine, is employed. The split skin is stored and dressings changed subsequently on the ward by the nursing staff while the patient remains in his bed.: Split skin is applied when the site is deemed by the 3 . surgeon to be in an optimal state to receive it.

Those patients who were to be given ketamine were fasted for $4 \mathrm{hr}$ beforehand. Anaesthesia was inducedô by an intravenous injection of ketamine $2 \mathrm{mg} / \mathrm{kg}$, which was mixed with atropine so that the firsto $400 \mathrm{mg}$ of ketamine was mixed with $0.6 \mathrm{mg}$, of $>$ atropine. A further dose of $4 \mathrm{mg} / \mathrm{kg}$ was given intramuscularly. Further doses were given when then patient made purposeful movements or when the nystagmus reappeared, after the initial nystagmus 0 which follows induction was over. At the end of the $\tilde{N}$ procedure a dose of $1 \mathrm{mg} / \mathrm{kg}$ was given intravenouslyo and the patient was left to recover consciousnesso completely undisturbed, but with a nurse present. Facilities for full resuscitation were present through-? out and the ketamine was always administered by an experienced anaesthetist. The value and acceptability of this method of anaesthesia was assessed by means 
of a questionnaire directed at the patient, the nursing staff and the anaesthetist.

The patients were asked their memories of the induction, the procedure and of recovery. Furthermore, they were asked if they would have any objection to being given a similar anaesthetic again, and whether they had any comments to make.

The nursing staff were asked whether the patient moved, and if so whether the movement interfered with the dressing procedure, whether the burned area bled, and if this interfered with the application of skin, and whether the patient recovered calmly.

The anaesthetist was asked whether there were any anaesthetic complications, what doses were given, and for any comments about the administration.

\section{Results}

In six children between 9 months and 8 years one anaesthetic was complicated because the child had been given milk to drink $3 \mathrm{hr}$ before the procedure. At this time the authors were unaware of the importance of an adequately long fasting period before the anaesthetic. This patient vomited and subsequently developed bronchopneumonia, but made an uneventful recovery.

Of ten adults aged between 24 and 74 years, one patient found the induction unpleasant, and one the recovery. However, neither of these patients found it so unpleasant that he would refuse a subsequent ketamine anaesthetic. Two patients objected to ketamine but neither complained of any specific unpleasant effect from the drug. One patient was disturbed in the recovery period, but this patient recovered in a noisy ward and not alone in a cubicle. In none of the patients did movement or bleeding interfere with the successful conduct of the change of dressing and application of split skin.

\section{Discussion}

Ketamine should meet many of the requirements of an anaesthetic that may be given with safety in the difficult environment of the patient's bed while offering at the same time many of the requirements of an adequate analgesic and anaesthetic for burns dressings. The airway is maintained and the cardiovascular system is stable, profound analgesia persists into the post-operative period and appetite is maintained. Respiration is not depressed unless an excessively fast, or excessively large intravenous dose is given. Many authors have recommended its use as an anaesthetic for burns surgery and dressing (Cohen, 1971; Corssen and Oget, 1971; Sage and Laird, 1972; Martinez and Grau Real, 1972; Wilson, Nichols and McCoy, 1967) and in difficult circum- stances (Boyd, Barry and Davies, 1971; Phillips et al., 1970), many of these making a particular point of its value in children. However, the very real problems presented by its side effects have prevented its really widespread adoption. Among these, in particular, is the problem of emergence delirium and hallucinations with unpleasant dreams. Together with these, the fact that the patient may move while anaesthetized, and that the elevation of blood pressure that accompanies ketamine anaesthesia may cause excessive bleeding at the burn site, have reduced its popularity.

It was hoped that, by a careful technique and, in particular, by making sure that the patient was fully anaesthetized at the end of the procedure and allowed to wake completely undisturbed, it would be possible to circumvent most of these complications while maintaining the advantages of ketamine used alone, avoiding the need for 'taming' adjuvants (Coppel, Bovill and Dundee, 1972).

In this small number of patients ketamine was found to be most satisfactory. Medically there were no problems, once the need for adequate fasting was established. Movement when present was not excessive and re-dressing and the application of graft were always possible. The only patient whose specific complaint was obviously related to the administration of ketamine was allowed to recover in a noisy, open ward. She did not find the experience so unpleasant as to refuse a further administration. Her experience confirms the value of recovery free from all forms of stimulation.

\section{References}

BAsketT, P.J.F. (1972) Analgesia for the dressing of burns in children: a method using neuroleptanalgesia and Entonox. Postgraduate Medical Journal, 48, 138.

Boyd, N.A., Barry, N.A. \& Davies, A.K. (1971) British surgical aid to Jordan. Annals of Royal College of Surgeons of England, 49, 291.

CoHEN, S. (1971) The use of ketamine hydrochloride in burns. In: Transactions of the Third International Congress on Research in Burns, Prague. Hans Huber Publishers, Bern, p. 668 .

Coppel, D.L., Bovill, J.G. \& Dundee, J.W. (1973) The taming of ketamine. Anaesthesia, 28, 293.

Corssen, G. \& OGET, S. (1971) Dissociative anesthesia for the severely burned child. Anesthesia and Analgesia, 50, 95.

Martinez, T.M. \& GraU Real, F. (1972) Use of ketamine chloride in anaesthesia for the burn patient. Revista Española Anestesiología y Reanimación, 19, 144.

Phillips, D.A., Seruvata, S.G., Rika, P.N. \& Tirihuia, V. (1970) Anaesthesia for the surgeon-anaesthetist in difficult situations. Anaesthesia, 25, 36.

SAGE, M. \& LAIRD, S.M. (1972) Ketamine anaesthesia for burns surgery. Postgraduate Medical Journal, 48, 156.

Wilson, R.D., Nichols, R.J. \& McCoY, N.R. (1967) Dissociative anesthesia in burned children. Anesthesia and Analgesia Current Researches, 49, 719. 